Correction

\title{
Correction: Lin. et al. Effects of Substrate-Coating Materials on the Wound-Healing Process. Materials 2019, 12, 2775
}

\author{
Jin-Young Lin ${ }^{1}$, Kai-Yin Lo ${ }^{2}(-)$ and Yung-Shin Sun ${ }^{1, *(1)}$ \\ 1 Department of Physics, Fu-Jen Catholic University, New Taipei City 24205, Taiwan; aasd59472@gmail.com \\ 2 Department of Agricultural Chemistry, National Taiwan University, Taipei 10617, Taiwan; kaiyin@ntu.edu.tw \\ * Correspondence: 089957@mail.fju.edu.tw; Tel.: +886-2-2905-2585
}

Received: 18 September 2019; Accepted: 2 January 2020; Published: 6 January 2020

check for updates

The authors wish to make the following correction to this paper [1]. Due to mislabeling, replace:

(a)

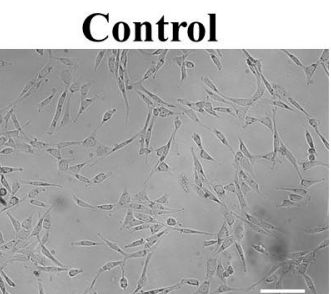

PLL

Gelatin
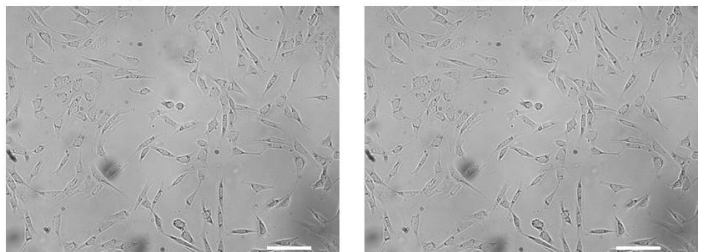

(b)

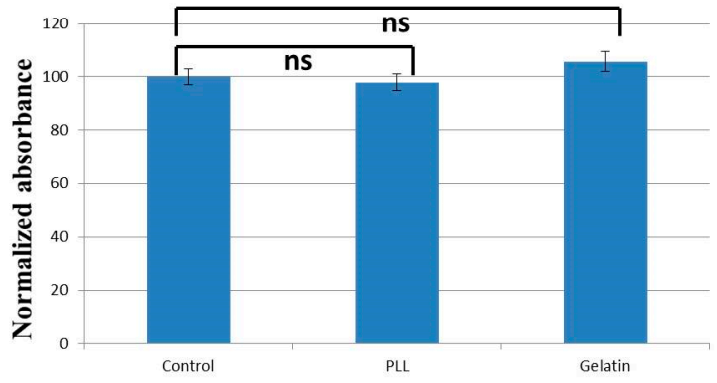

Figure 5. (a) Cells grown on uncoated (left), poly-L-lysine-coated (middle), and gelatin-coated (right) surfaces after $24 \mathrm{~h}$. Scale bar $=100 \mu \mathrm{m}$. (b) Cell proliferation/viability on different surfaces after $24 \mathrm{~h}$. Control: uncoated. PLL: Poly-L-lysine. Statistical analysis was performed on eight independent data points (see Section 2.2). Student's t-tests were performed. Ns: no statistically significant difference $(p>0.05)$.

with 
(a)

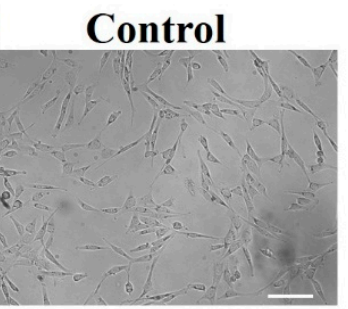

PLL
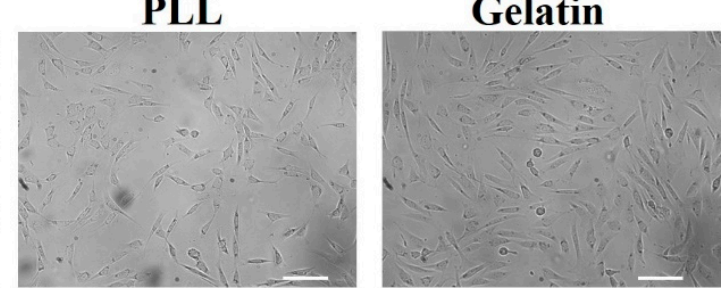

(b)

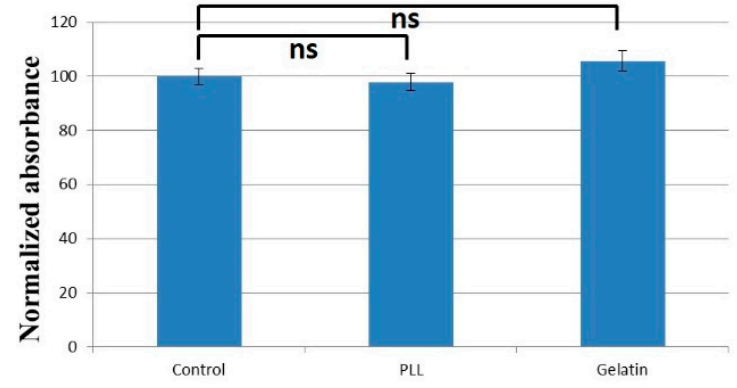

These changes have no material impact on the conclusions of the paper. The authors would like to apologize for any inconvenience caused to the readers by these changes.

Conflicts of Interest: The authors declare no conflicts of interest.

\section{Reference}

1. Lin, J.Y.; Lo, K.-Y.; Sun, Y.S. Effects of Substrate-Coating Materials on the Wound-Healing Process. Materials 2019, 12, 2775. [CrossRef] [PubMed]

(C) 2020 by the authors. Licensee MDPI, Basel, Switzerland. This article is an open access article distributed under the terms and conditions of the Creative Commons Attribution (CC BY) license (http://creativecommons.org/licenses/by/4.0/). 